\title{
Impact of T3 thoracoscopic sympathectomy on papillary function: a cause of partial Homer's syndrome?
}

\author{
Ricard Ramos
}

Received: 25 October 2012/Accepted: 11 January 2013/Published online: 31 January 2013

(C) Springer Science+Business Media New York 2013

Our study aimed to demonstrate that postganglionic axons of the sympathetic pathway can arise from the first three thoracic levels, even up to the fifth level.

I agree with the authors that there is variability in the anatomy of the thoracic sympathetic chain. We also have seen these variations in our anatomy department. The space between the third and fourth ribs allows access to the T3 sympathetic ganglion with its respective rami communicantes.
The fact that our patient with mild ptosis recovered in 3 months suggests that this patient may have had a larger number of preganglionic axons (via oculosympathetic) than the other patients.

This study has demonstrated that the T3 sympathetic ganglion may contain oculosympathetic pathway axons. Therefore, T3 ganglion injury also causes damage to the oculosympathetic, classified as mild or severe according to the number of axons reaching the ganglion.

R. Ramos $(\bowtie)$

Department of Thoracic Surgery, Hospital Universitari de

Bellvitge, Barcelona, Spain

e-mail: ricardramos@ub.edu 